\title{
Physical activity for human and planetary health
}

With Paris conference of parties on UN framework on climate change (COP21, 2015) reaching a landmark deal on the agreement for mitigating climate change, and several others international deliberations to follow by, we have the unique opportunity to find a solution common to both human and planetary health. Here we argue physical activity can be a link that transects human and planetary health.

Physical inactivity leads to many non-communicable diseases (NCDs) which has an immense health, economic and societal consequences. A total loss of 47 trillion dollars in next two decades is projected because of various NCDs (1). The 'physical-inactivity-epidemic' is slowly infiltrating all section of population including children of 9 to 15 years (2). Active commuting (walking or cycling to work, or study) have become less common as walking and cycling is replaced by vehicles. Also, use of public transport---which involves walking or cycling at the beginning or end of the journey---is replaced by use of cars and bikes. Manual labour is being extensively replaced by modern technologies in daily activities of living. This luxury has come with a price to our own health and the health of our planet.

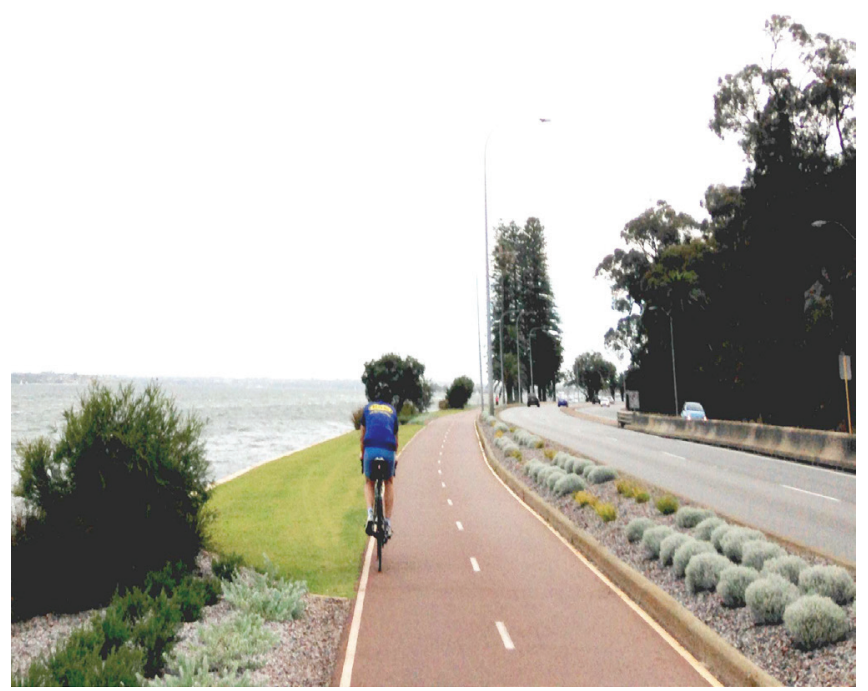

In 2013, an estimate shows that transportation sector alone contributed $27 \%$ of total carbon emissions in the US. Similarly, transportation sector in China, India, and other middle and high income countries substantially contributes to the global emission (3). In addition to that, extraction and refining of crude oils, manufacturing of vehicles, adds substantial emission to the atmosphere. Increasing reliance on electric appliances where the electricity is largely driven from coal fired plants also contribute to the emission. For instance, electricity in general, accounts a third of carbon emission in the US and this will continue to increase as the demand of electricity rise (3).

In current cities around the world concrete jungles are erupting rapidly which is not only have compromised our living standards it also has reduced the green space to lead a physically active life. In addition to that, bicycle lanes, adequate pedestrian lane, parks are often not considered and prioritized while constructing roads in many developed and underdeveloped countries with some exceptions. Reduction in green space reduces the carbon sinks, moreover makes environment less pleasant for any physical activity. Recent research has shown that green space in urban environments is associated with long term reduction in all-cause mortality (4), perceived higher level of general health (5), increased longevity among senior citizen living in areas with walkable green areas (6).

Promoting physical activity not just decreases transportation associated emissions, but also reduces deforestation in the world where forest are cleared up indiscriminately for petroleum extraction and coal mining, and also reduces logging of timbers for electricity plants that use coal. Thus, physical activity is a point where human and planetary health transects each other. It is a common agenda for climate-advocates and health educators, and should be advocated together.

\section{References}

1. Bloom DE, Cafiero E, Jané-Llopis E, Abrahams-Gessel S, Bloom LR, Fathima S, et al. The global economic burden of non communicable diseases. In: World Economic Forum, Harvard School of Public Health. Geneva: 2012. August 17 2015].

2. Nader PR, Bradley RH, Houts RM, Mcritchie SL \& O’brien M. 2008. Moderate-to-vigorous physical activity from ages 9 to 15 years. Jama, $300,295-305$.

3. United States Environment Protection Agency. 2013. Sources of Greenhouse Gas Emissions [Online]. EPA. Available: http://www.epa.gov/climatechange/ghgemissions/sources/transportation.html [Accessed December 4 2015].

4. Villenueve PJ, Jerrett M, Su JG, Burnett RT, Chen H, Wheeler AJ \& Goldberg MS. 2012. A cohort study relating urban green space with mortality in Ontario, Canada. Environ Res, 115, 51-8.

5. Maas J, Verheij RA, Groenewegen PP, De Vries S \& Spreeuwenberg P. 2006. Green space, urbanity, and health: how strong is the relation? J Epidemiol Community Health, 60, 587-592.

6. Takano T, Nakamura K \& Watanabe M. 2002. Urban residential environments and senior citizens' longevity in megacity areas: the importance of walkable green spaces. J Epidemiol Community Health, 56, 913-918. 